\title{
PROXIMITY OF MANDIBULAR THIRD MOLAR ROOTS WITH INFERIOR ALVEOLAR CANAL: A RADIOGRAPHIC STUDY
}

Ashutosh Kumar Singh ${ }^{1,}$, Nikita Khanal $^{1}$,Safal Dhungel ${ }^{1}$

${ }^{1}$ Department of Oral and Maxillofacial Surgery, College of Medical Sciences, Bharatpur, Nepal.

Received: 19 Dec, 2019
Accepted: 8 Mar, 2020
Published: 13 Mar, 2020
Key words: CBCT; Nerve injury; OPG; Radiographic
signs; Third molar.
$\quad$ *Correspondence to: Ashutosh Kumar Singh,
Department of Oral and Maxillofacial Surgery, College
$\quad$ of Medical Sciences, Bharatpur, Nepal.
$\quad$ Email: dr.ashutosh@cmsnepal.edu.np
DOI:https://doi.org/10.3126/jcmc.v10i1.28070
Citation
Singh AK, Khanal N, Dhungel S. Proximity of man-
dibular third molar roots with inferior alveolar ca-
nal: a radiographic study.Journal of Chitwan Medi-
cal College.2020;10(31):44-47.

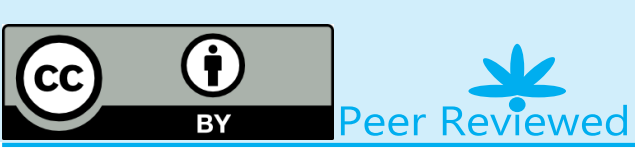

INTRODUCTION

Mandibular third molars are the most variable tooth in anatomy, root morphology and position of root with close proximity to inferior alveolar canal. This proximity, alongside the surgical techniques to remove these teeth have significant effect on the inferior alveolar nerve. ${ }^{1,2}$ Inferior alveolar nerve injuries are seen in 0.2 to $4 \%$ of surgically removed third molars with incidence dependent on multiple factors like age, sex, concomitant use of socket medications, experience and level of the surgeon, technique and instruments used for removal of the tooth. ${ }^{3,4}$ Preoperatively assessing the surgical difficulty with an Orthopantomogram (OPG), allow the surgeon to observe the morphology of the tooth, number of roots, angulation of tooth, its depth in the bone and the anterior ramus, which are factors affecting treatment plan. Several signs indicating the close relationship of third molar roots to the IAC has been proposed by Rood and Shebab and later by Poyton. ${ }^{5,6}$ Studies shows that OPG have nearly as good sensitivity and specificity of detecting close relationship between third molar roots and IAC as compared to a cone beam computed tomography and can be used for pre-assessment of third molars. ${ }^{7,8} \mathrm{OPG}$ 's are inexpensive, low radiation and easily available in smaller dental units and hospitals also however, a real three-dimensional picture and buccolingual relationship is unknown. Dearth of studies on third molar roots and inferior alveolar canal in Nepalese population persuaded us to carry out this study to describe the proximity of mandibular third molar roots to the inferior alveolar canal and nerve.

\section{METHODS}

A single centre cross-sectional study was designed with sample size of 475 patients collected from July 2017 to July 2019, at the department of Oral and maxillofacial surgery of College of Medical Sciences and Teaching Hospital (COMS-TH), Bharatpur, Nepal.

Ethical approval was obtained from institutional review committee of COMS-TH. All the patients who reported the signs and symptoms of third molar pain and difficulty were included. Pregnant patients and those who didn't provide consent were excluded. Orthopantomogram (OPG) of patients were retrieved from imaging software records. Baseline demographic data was obtained from patient's entry in OPG imaging software program (Orthoralix Vixwin software) and signs of proximity of mandibular third molar roots to inferior alveolar canal as 
described by Rood and Shebab were ascertained. ${ }^{7}$ The seven radiographic signs were observed on digitally magnified OPG's using Orthoralix Vixwin software (Gendex, USA) and presence or absence of signs were entered. Presence of simultaneous multiple signs were entered. Explicit prior criteria have been used to designate each of the seven panoramic radiographic signs as "positive" when present or "negative" when absent (Table 1). All observations and demographic datas were entered in Microsoft excel and descriptive analysis was performed with SPSS Version 20. Frequency was used to describe presence of radiographic signs and means were used to describe demographic variables. Cross tabulation was done to analyse the pattern of combination of signs.

Table 1: Criteria for presence or absence of radiographic signs on OPG

\begin{tabular}{|l|l|}
\hline Radiographic sign & Criteria for positive sign \\
\hline Diversion of the canal & $\begin{array}{l}\text { Change in direction of inferior } \\
\text { alveolar canal when it comes } \\
\text { on contact with root of third } \\
\text { molar }\end{array}$ \\
\hline $\begin{array}{l}\text { Interruption of white line } \\
\text { of canal }\end{array}$ & $\begin{array}{l}\text { Disappearance of one or both } \\
\text { cortical white line of inferior al- } \\
\text { veolar canal }\end{array}$ \\
\hline Narrowing of the canal & $\begin{array}{l}\text { Reduction in diameter of the } \\
\text { inferior alveolar canal when it } \\
\text { meets roots of third molar }\end{array}$ \\
\hline Darkening of root & $\begin{array}{l}\text { Increased radiolucency be- } \\
\text { cause of overlapping of the ca- } \\
\text { nal and roots of third molar }\end{array}$ \\
\hline Deflection of root & $\begin{array}{l}\text { Abrupt deviation of third molar } \\
\text { roots when it reaches the canal }\end{array}$ \\
\hline Narrowing of the root & $\begin{array}{l}\text { Abrupt narrowing of the third } \\
\text { molar root when it overlaps } \\
\text { with the inferior alveolar canal }\end{array}$ \\
\hline Dark and bifid apex of the \\
root & $\begin{array}{l}\text { Double shadow of periodontal } \\
\text { membrane when roots cross } \\
\text { the inferior alveolar canal }\end{array}$ \\
\hline
\end{tabular}

\section{RESULTS}

Distribution of Age (years)

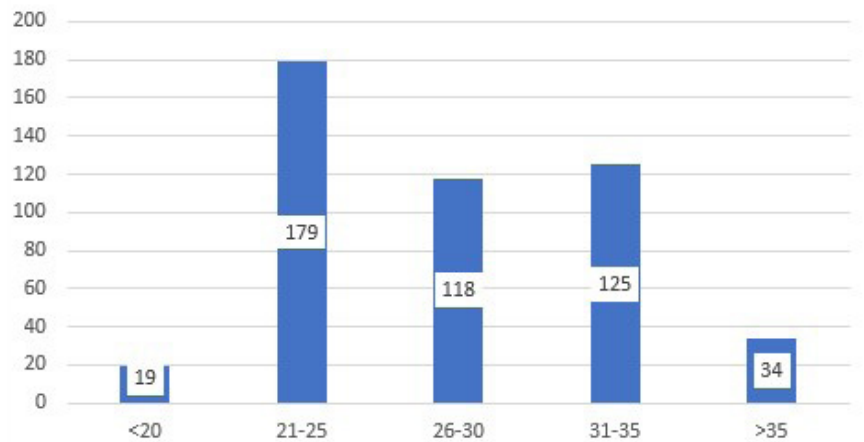

Figure 1: Distribution of age in the study population gender distribution

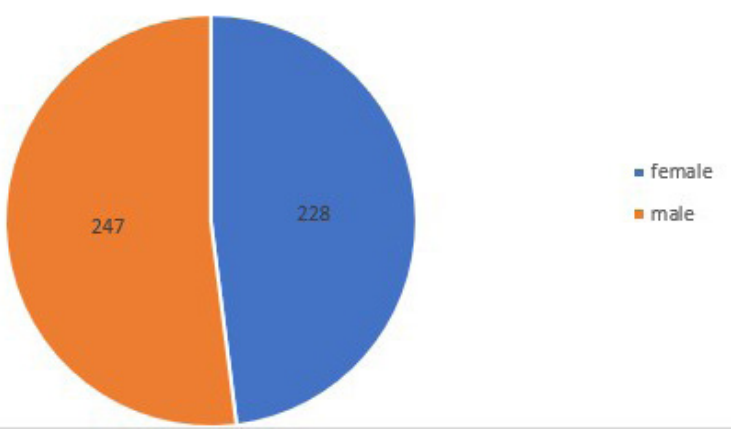

Figure 2: Distribution of gender in the study population

The distribution of age group is shown in Figure 1, and the distribution of gender in Figure 2, in the study population.

Most common age group in our study were 21-25 years age $(n=179)$ followed by $31-35$ years of age $(n=125)$. There were almost equal number of male $(n=247)$ and female $(n=228)$ in this study (Figure 2).

The most common radiographic sign was interruption of white line of Inferior alveolar canal $(n=196)$ followed by narrowing of canal $(n=113)$ and darkening of $\operatorname{roots}(n=110)$ as shown in Table 2.

Table 2: Prevalence of individual radiographic signs in the population.

\begin{tabular}{|l|l|l|}
\hline Radiographic Signs & Yes & No \\
\hline Darkening of root & $110(23.16)$ & $365(76.84)$ \\
\hline Deflection of root & $49(10.32)$ & $426(89.68)$ \\
\hline Interrupted white line & $196(41.26)$ & $279(58.74)$ \\
\hline Narrowing of IAC & $113(23.79)$ & $362(76.21)$ \\
\hline Diversion of IAC & $30(6.32)$ & $445(93.68)$ \\
\hline Dark and bifid root & $20(4.21)$ & $455(95.79)$ \\
\hline Narrowing of root & $32(6.74)$ & $443(93.26)$ \\
\hline
\end{tabular}

Absence of any radiographic sign was observed in 245 cases $(51.6 \%)$. When only one sign was observed $(n=71)$, the most common sign was, interruption of white line of canal followed by deflection of roots. The next most common pattern of combination was 3 signs $(n=60)$ followed by two signs together $(n=55)$.

The common pattern of two signs seen together were interruption of white line and darkening of roots. The common pattern when three signs were seen together was interruption of white line of canal, narrowing of canal and darkening of roots (Table $3)$. 
Table 3: Prevalence of multiple signs and their combinations

\begin{tabular}{|l|l|l|l|l|l|l|l|l|l|}
\hline $\begin{array}{l}\text { Radio- } \\
\text { graphic } \\
\text { sign }\end{array}$ & $\begin{array}{l}\text { Preva- } \\
\text { lence }\end{array}$ & $\begin{array}{l}\text { Percent- } \\
\text { age }\end{array}$ & $\begin{array}{l}\text { Darken- } \\
\text { ing of } \\
\text { root }\end{array}$ & $\begin{array}{l}\text { Deflec- } \\
\text { tion of } \\
\text { root }\end{array}$ & $\begin{array}{l}\text { Interrupt- } \\
\text { ed white } \\
\text { line }\end{array}$ & $\begin{array}{l}\text { Narrow- } \\
\text { ing of IAC }\end{array}$ & $\begin{array}{l}\text { Diversion } \\
\text { of IAC }\end{array}$ & $\begin{array}{l}\text { Dark and } \\
\text { bifid root }\end{array}$ & $\begin{array}{l}\text { Narrow- } \\
\text { ing of } \\
\text { root }\end{array}$ \\
\hline 0 & 245 & 51.6 & & & & & & & \\
\hline 1 & 71 & 14.9 & 7 & 24 & 37 & 0 & 2 & 0 & 1 \\
\hline 2 & 55 & 11.6 & 26 & 8 & 55 & 19 & 1 & 1 & 0 \\
\hline 3 & 60 & 12.6 & 38 & 6 & 60 & 51 & 9 & 3 & 13 \\
\hline 4 & 31 & 6.5 & 26 & 7 & 31 & 30 & 10 & 8 & 12 \\
\hline 5 & 13 & 2.7 & 13 & 4 & 13 & 13 & 8 & 8 & 6 \\
\hline Total & 475 & & 110 & 49 & 196 & 113 & 30 & 20 & 32 \\
\hline
\end{tabular}

No significant correlation was found between demographic variables of age, sex and side of impaction and presence or absence of radiographic signs of proximity of third molar roots to inferior alveolar canal with significance level fixed at $p=<0.05$ at $95 \%$ confidence level.

\section{DISCUSSION}

Radiographic signs showing proximity of third molar roots to inferior alveolar canal has been used to correlate the neurosensory injury to inferior alveolar nerve when third molar roots are anatomically close to the inferior alveolar canal as evident by radiographic signs. Rood and Shehab found a significant relation between diversion of the canal, narrowing of the root, interruption of the white line by the nerve, and injury to the nerve. ${ }^{9}$ Some studies show that the bone line of the mandibular canal is more likely to be interrupted by the impacted tooth if panoramic radiography shows the impacted tooth intersecting the mandibular canal, and it is also more likely to come into contact with the canal if the root of the impacted tooth is narrowing. ${ }^{10,11}$ Other study too have reported that the impacted tooth is more likely to come into contact with the canal if the white line cannot be identified on panoramic radiography. ${ }^{12}$ With positive panoramic radiographic signs of diversion of the canal, interruption of white line of the canal or darkening of the root, the risk of inferior alveolar nerve injury after third molar surgery was shown to increase between 8 - 22\%.,8,12 Hence, the presence of the panoramic radiographic signs of diversion of the canal, interruption of white line of the canal or darkening of the root had sufficient added value for ruling in the IAN injury during mandibular third molar surgery and these signs were similarly observed most frequently in this study. The other four signs were not observed frequently which was similar to the observation in this study and, studies have shown that these four signs do not have adequate predictive value to support further investigations with a CBCT. ${ }^{13,14}$ In the prospective study by Rood and Shehab, with signs suggesting an increased risk of nerve involvement, nerve injury was observed in $14 \%$ of cases. ${ }^{5}$ The Howe and Poyton study also used radiological predictors as stated above, nerve injury incidence was observed in $35.64 \% .{ }^{6}$ Hence, using radiographic predictors during pre-operative planning, can be a useful tool to reduce the incidence of nerve injuries associated with surgical removal of third molars. Further investigations with a CBCT can be performed to confirm the three dimensional association of third molar roots to the inferior alveolar canal and surgery can be modified to minimize risk of injury. ${ }^{15-17}$ Intentional and partial coronectomy can be performed for roots which show radiographic signs most associated with nerve injuries. ${ }^{18,19}$ In our clinical experience, if there is presence of radiographic signs that suggest anatomical proximity of inferior alveolar canal with third molar roots, it is always prudent to make sure that the tooth is elevated gently from the socket and root apex visualized, before complete removal from the socket. Orthodontic extrusion and extraction can be an alternative in high risk cases. ${ }^{20}$ Multi rooted third molars with proximity to inferior alveolar canal should be removed after division of roots to minimise traction injury to the inferior alveolar nerve if the roots are hooked around the nerve. By following these simple rules, we have observed minimal incidence of inferior alveolar nerve injuries during surgical removal of mandibular third molars in our own unit. ${ }^{21}$

This study is not devoid of limitations. First of all, this is a simple cross-sectional study where radiographic signs were observed on an OPG. Newer studies in developed countries and health systems use CBCT to confirm the proximity of third molar roots to the inferior alveolar nerve in three dimensions. Because of relative unavailability of $\mathrm{CBCT}$ in our country and relatively higher expense of $\mathrm{CBCT}$, precludes its use in our patient population. We recommend $\mathrm{CBCT}$ only if there is high possibility of post-operative nerve damage and use OPG as a predicative tool routinely before surgical removal of third molars. This is a single centre study so the outcomes of this study cannot be generalized. A cross sectional prevalence study is the first step towards clinical studies where complications of nerve injury and should be correlated with the radiographic signs on OPG and comparative study between diagnostic accuracy of OPG and $\mathrm{CBCT}$ should be planned in the future.

\section{CONCLUSION}

Radiographic signs indicating proximity of mandibular third molars with inferior alveolar canal are seen very frequently on OPG and OPG can be used as a predictive tool to anticipate risk of inferior alveolar nerve injury. When interruption of white line of canal, diversion of canal and darkening of roots of mandibular third molar is seen on OPG, a high suspicion of nerve injury should be made and a CBCT should be advised in such cases. 


\section{REFERENCES:}

1. Leung YY, Cheung LK. Correlation of radiographic signs, inferior dental nerve exposure, and deficit in third molar surgery. Journal of Oral and Maxillofacial Surgery. $2011 \mathrm{Jul} ; 69(7): 1873-9$. [DOI]

2. Juodzbalys G, Wang H-L. Guidelines for the identification of the mandibular vital structures: practical clinical applications of anatomy and radiological examination methods. JOMR [Internet]. 2010 Apr 23 [cited 2020 Feb 18];1(2). [LINK]

3. Valmaseda-Castellón E, Berini-Aytés L, Gay-Escoda C. Inferior alveolar nerve damage after lower third molar surgical extraction: A prospective study of 1117 surgical extractions. Oral Surgery, Oral Medicine, Oral Pathology, Oral Radiology, and Endodontology. 2001 Oct;92(4):377-83. [DOI]

4. Céspedes-Sánchez JM, Ayuso-Montero R, Marí-Roig A, Arranz-Obispo C, López-López J. The importance of a good evaluation in order to prevent oral nerve injuries: A review. Acta Odontologica Scandinavica. 2014 Apr;72(3):161-7. [DOI]

5. Huang $\mathrm{C}-\mathrm{K}$, Lui MT, Cheng $\mathrm{DH}$. Use of panoramic radiography to predict postsurgical sensory impairment following extraction of impacted mandibular third molars. Journal of the Chinese Medical Association. 2015 Oct;78(10):617-22. [DOI]

6. Carter K, Worthington S. Predictors of third molar impaction: a systematic review and meta-analysis. J Dent Res. 2016 Mar;95(3):267-76. [DOI]

7. Rood JP, Nooraldeen Shehab BAA. The radiological prediction of inferior alveolar nerve injury during third molar surgery. British Journal of Oral and Maxillofacial Surgery. 1990 Feb;28(1):20-5. [DOI]

8. Howe GL, Poyton HG. Prevention of damage of the inferior dental nerve during the extraction of mandibular third molars. Br Dent J 1960;109:35563

9. Kamadjaja DB, Asmara D, Khairana G. The correlation between Rood and Shehab's radiographic features and the incidence of inferior alveolar nerve paraesthesia following odontectomy of lower third molars. Dental Journal Majalah Kedokteran Gigi. 2016;49(2):59-62. [DOI]

10. Sedaghatfar M, August MA, Dodson TB. Panoramic radiographic findings as predictors of inferior alveolar nerve exposure following third molar extraction. Journal of Oral and Maxillofacial Surgery. 2005 Jan;63(1):3-7. [DOI]

11. Atieh MA. Diagnostic accuracy of panoramic radiography in determining relationship between inferior alveolar nerve and mandibular third molar.
Journal of Oral and Maxillofacial Surgery. 2010 Jan;68(1):74-82. [DOI]

12. Ghaeminia H, Meijer GJ, Soehardi A, Borstlap WA, Mulder J, Bergé SJ. Position of the impacted third molar in relation to the mandibular canal. Diagnostic accuracy of cone beam computed tomography compared with panoramic radiography. International journal of oral and maxillofacial surgery. 2009 Sep 1;38(9):964-71. [DOI]

13. Blaeser BF, August MA, Donoff RB, Kaban LB, Dodson TB. Panoramic radiographic risk factors for inferior alveolar nerve injury after third molar extraction. Journal of oral and maxillofacial surgery. 2003 Apr 1;61(4):41721. [DOI]

14. Hasegawa T, Ri S, Shigeta T, Akashi M, Imai Y, Kakei Y, Shibuya Y, Komori T. Risk factors associated with inferior alveolar nerve injury after extraction of the mandibular third molar-a comparative study of preoperative images by panoramic radiography and computed tomography. International journal of oral and maxillofacial surgery. $2013 \mathrm{Jul}$ 1;42(7):843-51. [DOI]

15. Harada N, Vasudeva SB, Matsuda Y, Seki K, Kapila R, Ishikawa N, Okano T, Sano T. Characteristic findings on panoramic radiography and cone-beam CT to predict paresthesia after extraction of impacted third molar. The Bulletin of Tokyo Dental College. 2015;56(1):1-8. [DOI]

16. Ghaeminia $\mathrm{H}$, Gerlach $\mathrm{NL}$, Hoppenreijs TJ, Kicken $\mathrm{M}$, Dings JP, Borstlap WA, De Haan T, Bergé SJ, Meijer GJ, Maal TJ. Clinical relevance of cone beam computed tomography in mandibular third molar removal: A multicentre, randomised, controlled trial. Journal of Cranio-Maxillofacial Surgery. 2015 Dec 1;43(10):2158-67. [DOI]

17. Gallesio C, Berrone M, Ruga E, Boffano P: Surgical extraction of impacted inferior third molars at risk for inferior alveolar nerve injury. J Craniofac Surg 2010 Nov;21(6):2003-7. [DOI]

18. Patel V, Moore S, Sproat C. Coronectomy - oral surgery's answer to modern day conservative dentistry. Br Dent J. 2010 Aug;209(3):111-4. [DOI]

19. Long H, Zhou Y, Liao L, Pyakurel U, Wang Y, Lai W. Coronectomy vs. Total removal for third molar extraction: a systematic review. J Dent Res. 2012 Jul;91(7):659-65. [DOI]

20. Bonetti GA, Bendandi M, Laino L, Checchi V, Checchi L. Orthodontic extraction: riskless extraction of impacted lower third molars close to the mandibular canal. Journal of oral and maxillofacial surgery. $2007 \mathrm{Dec}$ 1;65(12):2580-6. [DOI]

21. Singh AK: Complications Associated with Surgical Removal of Mandibular Third Molar: A Prospective Study. J Nep Dental Association 2019 Jan 19(1):10-15 